\title{
ACTS, DISPOSITIONS, AND CLINICAL ASSESSMENT: THE PSYCHOPATHOLOGY OF EVERYDAY CONDUCT
}

\author{
David M. Buss \\ Department of Psychology \\ University of Michigan \\ Ann Arbor, MI 48109-1346 \\ Kenneth H. Craik \\ Institute of Personality Assessment and Research \\ University of California, Berkeley, CA 94720
}

Manifestations of psychopathology typically are noted first in the context of a person's everyday life. The inability to work or play, displays of unusual behavior or ideation, expressions of subjective distress, and behaviors injurious to self or others initially come to the attention of family, friends, co-workers, and other members of society. Only subsequently do persons encounter mental health professionals and receive psychiatric diagnosis and treatment. In contrast to the wide-ranging manifestations of psychopathology in everyday life, the typical settings for forming diagnostic judgments, such as the interview room or the psychiatric ward, provide more restricted contexts that limit the range of behaviors likely to be displayed and observed. An important goal of clinical assessment, therefore, should be to preserve the links between psychiatric diagnostic classifications and the psychopathology of everyday conduct.

The act frequency approach to personality (Buss \& Craik, 1980, 1981, 1983a, 1984 , in press; also see Wiggins, 1981) represents a systematic analysis of dispositional constructs (e.g., dominance, quarrelsomeness) as categories of acts occurring in everyday human conduct (e.g., monopolizing the conversation, or picking a fight with the stranger at the party). This article outlines the implications of the act frequency approach for clinical assessment generally, and its application to the personality disorders classified in the DSM-III specifically (American Psychiatric Association, 1980).

The first two sections describe the basic framework of the act frequency approach and its research and assessment methods. Categories of acts for the dispositions

Requests for reprints should be sent to: David M. Buss, Department of Psychology, University of Michigan, Ann Arbor, MI 48109-1346. 
of quarrelsome and submissive illustrate the framework in the context of clinicallytoned everyday acts. The third section describes the application of the act frequency approach to clinical assessment. This agenda includes the analysis of clinicallyrelevant dispositions drawn from the natural language, act prototypicality analysis of dispositional constructs relevant to the DSM-III categories, and a detailed act prototypicality analysis of alternative approaches to portraying the personality disorder syndromes of the DSM-III. The fourth section contrasts the act frequency approach with other strategies and orientations such as personality scale assessment (e.g., the Minnesota Multiphasic Personality Inventory [MMPI]), behavioral assessment (e.g., Goldfreid \& Kent, 1972), and exemplar prototype analysis (e.g., Cantor \& Genero, in press; Cantor, Smith, French, \& Mezzich, 1980). The final section draws implications for the clinical assessment of individuals in everyday life contexts and settings.

\section{THE ACT FREQUENCY APPROACH TO DISPOSITIONAL ANALYSIS}

The act frequency approach begins with the premise that the fundamental goal of classificatory systems in personality and clinical psychology is to describe and account for regularities in individuals' actions, broadly conceived, occurring throughout the natural flow of everyday conduct (Buss \& Craik, 1983c, 1984). Dispositions are conceptual units that summarize general trends, or act frequencies, in conduct. Dispositional constructs guide most personality research, and compose subunits of the broader personality disorder syndromes described in the DSM-III.

To say that Harry is hostile, from the act frequency perspective, means that he has displayed a high frequency of hostile acts over a designated period of observation. Dispositional concepts such as hostile capture descriptive regularities in everyday conduct. Saying that Harry is hostile, however, does not explain why he picked a fight with the stranger at the party, slammed the door when he left the room, made belittling comments about the people who walked by, or hit someone who annoyed him. In this sense, the act frequency approach shares with the DSM-III the orientation of clearly separating descriptive from explanatory tasks (American Psychiatric Association, 1980, p. 7).

As objects are basic elements of the inanimate world, acts are the basic elements of the world of human conduct. The network of dispositional constructs provides a fundamental system for categorizing acts by partitioning and granting conceptual order to the everyday flow of conduct. An intriguing feature of dispositional constructs is that they subsume individual acts that are often widely dispersed in time. In contrast, scriptal units (e.g., the restaurant script) subsume temporally contiguous act sequences (cf., Abelson, 1981). In this sense, dispositional constructs, as well as syndromes that subsume them, are highly selective, chunking acts that are extracted from temporally different points along the behavioral stream. Dispositions summarize the relative frequency of these temporally dispersed acts.

Although dispositions, from the act frequency perspective, serve this basic descriptive function, and therefore do not explain the act trends they summarize, manifested act trends subsumed by dispositional constructs are far from powerless or inconsequential. Indeed, dispositional act trends can affect causally how individuals describe themselves (self-concept), how they are described by others (attributions and reputation), and the significant life outcomes that emerge over time in the person's fate in society. High frequencies of hostile acts can evoke angry act trends from others (Buss, 1985a), thereby confirming, for example, a self-concept that involves persecu- 
tion and grandeur, a reputation as troublesome, and a life-history of repeated firings from different jobs. These causal impacts of act trends remain one of the most important domains for programmatic research.

The act frequency approach shares with lexical approaches (e.g., Allport \& Odbert, 1936; Cattell, 1946; Goldberg, 1982; Norman, 1963; Wiggins, 1979) the assumption that many dispositional constructs are sociocultural products that have evolved to capture important performance phenomena. As linguistic products, dispositional constructs can be analyzed by their cognitive features, two of which are especially relevant. First, dispositional categories are treated as "fuzzy sets" (Zadeh, Fu, Tanaka, \& Shimura, 1975). That is, category boundaries are not sharply demarcated and different categories blend into one another, just as the color red blends into orange and purple. Second, not all act members within a given dispositional category possess equal status within it. Some are more central and others more peripheral, just as some red objects are "redder" than others and some birds (e.g., robins, sparrows) are more "birdlike" than others (e.g., penguins, turkeys).

Rosch and her colleagues (Rosch, 1975; Rosch \& Mervis, 1975; Rosch, Simpson, \& Miller, 1976) have conceptualized the differing cognitive status of category members in terms of the notion of prototypicality. Highly prototypical members are the clearest cases, the best examples, the instances par excellence of the category. Thus, dispositional categories are composed of topographically distinct acts that differ in their within-category status from highly central or prototypical to progressively more peripheral, until the fuzzy boundaries are reached and adjoining categories are entered.

In sum, the act frequency approach treats dispositional constructs as sociocultural emergents that capture important descriptive regularities in everyday conduct (Buss \& Craik, 1983c, in press). These regularities consist of the relative frequencies with which acts within the category are performed by persons during a period of observation. Dispositions in this sense are not viewed as causal or explanatory. However, the assessed act trends subsumed by them carry considerable potency in affecting self-concept, observer attributions, reputation, and significant life outcomes. Analysis of the cognitive features of category fuzziness and the prototypicality of category members facilitates the precision with which dispositions, and the acts subsumed by them, can be analyzed and understood as sociocultural emergents.

\section{ASSESSMENT METHODS OF ACT FREQUENCY ANALYSIS}

The use of dispositional constructs in the act frequency approach generates a program of research based on their analysis (Buss \& Craik, 1984). There are three basic components to this personality assessment agenda: (1) identifying the internal cognitive structure of dispositions by exploring the acts subsumed by them and the status of specific acts with respect to dispositional categories, (2) using the information acquired from the cognitive mapping as a basis for charting manifested frequencies of acts as they occur in the everyday lives of persons, and (3) assessing the impact of acts and act trends on the person's social and physical environment and the life-outcome consequences for the individual.

\section{Act Nominations}

The first step in this research program entails identifying specific acts that are subsumed by each dispositional category. Act nominations can occur "on-line" (e.g., from direct observation by peers, family members, or clinicians) or retrospective- 
ly. One instructional set that has been used is: "Think of the three most quarrelsome [submissive, calculating, narcissistic, etc.] individuals you know. With these individuals in mind, write down five specific acts or behaviors that they have performed that reflect or exemplify their quarrelsomeness [submissiveness, . . . ]." These nomination procedures were designed to retrieve a large number of specific acts (100 or more) within each dispositional category. Examples of acts from the quarrelsome act category are: I cursed at my parents, I criticized him for failing to put his napkin on his lap, I insisted on having the last word in the discussion, and I slammed the door when I left the room.

\section{Prototypicality Ratings}

For each set of acts generated through nomination procedures, panels of judges rate the prototypicality of each act. Instructions for this task were adapted from Rosch and Mervis (1975) in the domain of colors:

Close your eyes and imagine a true red. Now imagine an orangish red . . imagine a purple red. Although you might still name the orange-red or the purple-red with the term red, they are not as good examples of red (as clear cases of what red refers to) as the clear "true" red. In short, some reds are redder than others."

In this specific study, you are asked to judge how good an example of a category various instances of the category are. The category is [quarrelsomeness, submissiveness, etc.]. Below are listed 100 acts. You are to rate how good an example of that category each act is on a 7-point scale. A "7" means that you feel the act is a very good example of your idea of what [quarrelsomeness, etc.] is; a " 1 " means you feel the act fits very poorly with your idea of what is (or is not a member of that category at all). A " 4 " means that you feel the act fits moderately well. Use other numbers on the 7 -point scale to indicate intermediate judgments.

The purpose of this procedure is to identify the consensual prototypicality judgment of each act for the disposition in which it was initially nominated. Panels of judges show reasonable agreement as indexed by alpha reliability coefficients (Buss \& Craik, 1983a, 1984). Examples of quarrelsome and submissive acts differing in prototypicality are shown in Tables 1 and 2. These acts were in part selected to give a flavor of clinically-toned actions in everyday conduct. Giving someone the "silent treatment," for example, seems prototypical of passive-aggressiveness, while accusing others of talking behind one's back suggests suspiciousness or mild paranoid tendencies. This latter act gives support to Wiggins' (1982) hypothesized mapping of DSM-III Paranoid Personality Disorder onto the quarrelsome octant of his circumplex structure.

The submissive acts listed in Table 2 also suggest a clinical tone to these occurrences in everyday conduct. Accepting verbal abuse without defending oneself, agreeing that one is wrong even though not, and walking out of a store knowing that one has been short-changed seem somewhat masochistic. These illustrations tend to support Wiggins' (1982) placement of masochism in the submissive (HI) octant of his circumplex model of the interpersonal domain.

\section{Multiple Dispositional Act Sorting}

Although prototypicality ratings yield simple and direct indices of the differential status of acts, they undoubtedly underestimate the complexity of the multiple constructs that may be used to interpret each act. In personality and clinical psychology, 
TABLE 1. Quarrelsome Acts Differing in Prototypicality

\begin{tabular}{|c|c|c|c|c|}
\hline \multicolumn{2}{|c|}{ Endorsement $\%^{1}$} & \multicolumn{2}{|c|}{ Prototypicality ${ }^{2}$} & \multirow[b]{2}{*}{ Quarrelsome Acts } \\
\hline Male & Female & $\operatorname{He} \bar{X}$ & She $\bar{X}$ & \\
\hline 02 & 06 & 6.54 & 6.59 & I picked a fight with the stranger at the party. \\
\hline 02 & 06 & 6.43 & 6.45 & I slapped him when he didn't agree with me. \\
\hline 04 & 04 & 5.96 & 5.90 & $\begin{array}{l}\text { I wrote a hate letter to an old boyfriend/girl- } \\
\text { friend. }\end{array}$ \\
\hline 64 & 63 & 5.18 & 5.14 & $\begin{array}{l}\text { I made belittling comments about the people } \\
\text { who walked by. }\end{array}$ \\
\hline 58 & 78 & 4.82 & 5.10 & $\begin{array}{l}\text { I gave him/her the "silent treatment" when I } \\
\text { was upset. }\end{array}$ \\
\hline 29 & 25 & 5.14 & 4.72 & $\begin{array}{l}\text { I twisted my friend's words around to make } \\
\text { his/her comments sound insulting. }\end{array}$ \\
\hline 44 & 67 & 4.29 & 4.97 & $\begin{array}{l}\text { I ended the conversation by stalking out of the } \\
\text { room. }\end{array}$ \\
\hline 07 & 05 & 4.75 & 4.48 & $\begin{array}{l}\text { I criticized every suggestion that was made at } \\
\text { the meeting. }\end{array}$ \\
\hline 16 & 18 & 4.61 & 4.35 & I stole food from my roommate. \\
\hline 37 & 47 & 3.29 & 3.45 & $\begin{array}{l}\text { I condemned others for over-indulging in food } \\
\text { and drink. }\end{array}$ \\
\hline 09 & 08 & 3.39 & 3.21 & I made fun of him for having a runny nose. \\
\hline 24 & 41 & 3.04 & 3.03 & I turned down my steady on a Saturday night. \\
\hline 64 & 51 & 2.68 & 3.17 & I criticized him for smoking. \\
\hline 78 & 73 & 2.75 & 2.90 & I argued about the presidential candidates. \\
\hline 58 & 78 & 2.71 & 2.76 & $\begin{array}{l}\text { I complained about how others were mistreat- } \\
\text { ing me. }\end{array}$ \\
\hline 53 & 63 & 2.68 & 2.72 & I exaggerated my personal problems. \\
\hline 33 & 37 & 2.89 & 2.72 & I insisted on doing the driving on the trip. \\
\hline
\end{tabular}

'Endorsement percentages reflect the percentage of this sample of undergraduates $(N=100)$ who reported performing the act at least once.

${ }^{2}$ Prototypicality ratings refer to the mean rating, on a 7-point scale, of the centrality of the act to the quarrelsome category $(N=29)$.

few acts are unambiguously pathognomonic, or invariantly indicative of a single disposition or disorder. Some acts may signify more than one dispositional construct, just as some symptoms may signify more than one diagnostic category. To explore this complexity, a multiple dispositional sorting and rating procedure was devised (Buss \& Craik, 1986).

Eight hundred act descriptions, previously nominated within eight dispositional categories, were typed onto 3 " $\times 5$ " index cards, with one act per card. Panels of judges were asked to sort and rate each act with respect to each of the eight dispositional categories. The 800 acts were shuffled randomly for each subject, to disperse order effects. Each act was first sorted into the category or categories within which 
TABLE 2. Submissive Acts Differing in Prototypicality

\begin{tabular}{|c|c|c|c|c|}
\hline \multicolumn{2}{|c|}{ Endorsement $\%^{1}$} & \multicolumn{2}{|c|}{ Prototypicality ${ }^{2}$} & \multirow[b]{2}{*}{ Submissive Acts } \\
\hline Male & Female & $\operatorname{He} \bar{X}$ & She $\bar{X}$ & \\
\hline 42 & 41 & 5.77 & 5.81 & $\begin{array}{l}\text { I agreed that I was wrong, even though I } \\
\text { wasn't. }\end{array}$ \\
\hline 24 & 20 & 5.59 & 5.48 & $\begin{array}{l}\text { I smoked marijuana when everyone else did, } \\
\text { even though I didn't want to. }\end{array}$ \\
\hline 29 & 14 & 5.44 & 5.48 & $\begin{array}{l}\text { I walked out of the store knowing that I'd been } \\
\text { short-changed }\end{array}$ \\
\hline 47 & 57 & 5.40 & 5.25 & $\begin{array}{l}\text { I accepted verbal abuse without defending } \\
\text { myself. }\end{array}$ \\
\hline 27 & 53 & 4.96 & 5.67 & $\begin{array}{l}\text { I made love with my partner when I didn't } \\
\text { want to. }\end{array}$ \\
\hline 27 & 27 & 5.08 & 5.08 & $\begin{array}{l}\text { When I stood to speak and the others con- } \\
\text { tinued talking, I simply sal down. }\end{array}$ \\
\hline 64 & 63 & 4.13 & 4.44 & I continued to apologize for the minor mistake. \\
\hline 11 & 18 & 3.92 & 4.33 & $\begin{array}{l}\text { I drank a lot at the party when the others gave } \\
\text { me a hard time. }\end{array}$ \\
\hline 33 & 35 & 4.02 & 4.21 & $\begin{array}{l}\text { I listened quietly when my parents said that } \\
\text { my hair was ugly. }\end{array}$ \\
\hline 58 & 76 & 4.08 & 4.27 & $\begin{array}{l}\text { I was not able to tell my friend that I was } \\
\text { angry with her. }\end{array}$ \\
\hline 84 & 78 & 3.98 & 4.02 & $\begin{array}{l}\text { At the meeting, I let others monopolize the } \\
\text { conversation. }\end{array}$ \\
\hline 16 & 51 & 4.04 & 3.81 & $\begin{array}{l}\text { I wept when I couldn't solve the simple } \\
\text { problem. }\end{array}$ \\
\hline 56 & 69 & 3.27 & 3.29 & $\begin{array}{l}\text { I said "thank-you" enthusiastically and } \\
\text { repeatedly when someone did me an insignifi- } \\
\text { cant favor. }\end{array}$ \\
\hline 33 & 33 & 3.40 & 2.96 & $\begin{array}{l}\text { I avoided direct eye contact when the shop } \\
\text { clerk spoke to me. }\end{array}$ \\
\hline 18 & 25 & 3.08 & 3.10 & $\begin{array}{l}\text { I did not start a single conversation at the } \\
\text { party. }\end{array}$ \\
\hline 29 & 57 & 3.02 & 2.77 & $\begin{array}{l}\text { Although my friends thought my partner had } \\
\text { humiliated me, I date him/her again. }\end{array}$ \\
\hline 24 & 86 & 2.67 & 2.56 & I blushed when he stared at me. \\
\hline 29 & 61 & 2.56 & 2.54 & $\begin{array}{l}\text { I pretended I was ill when declining the invi- } \\
\text { tation to the party. }\end{array}$ \\
\hline
\end{tabular}

${ }^{1}$ Endorsements reflect the percentage of males and fernales in this sample of undergraduates $(N=100)$ who reported performing the act at least once.

${ }^{2}$ Prototypicality ratings refer to the mean ratings, for he and she as actor, of the centrality of the act to the submissive category on a 7 -point scale $(N=47)$. 
it was perceived to belong. Multiple category placement was permitted, and subjects were encouraged to nominate alternative categories to the eight provided if the act was judged to belong in categories other than those provided. Following the multiple sorting, each act was rated on its prototypicality for each of the categories within which it was placed.

This multiple sorting procedure has yielded intriguing findings that were not uncovered by the more direct prototypicality ratings. Here, we will note only one type of finding: cross-dispositional categorization. Initially, our categories of quarrelsome and submissive were drawn from the Wiggins circumplex model of interpersonal behavior (Wiggins, 1979, 1980). One strong advantage of this model over an unstructured list is that it provides predictions about the types of cross-dispositional links that are more- and less-likely to occur. Because quarrelsome and submissive are orthogonal on the circumplex model, it may be predicted that few acts would be cross-dispositionally categorized using these two. In contrast, the introverted catcgory falls between quarrelsome and submissive. Therefore, both of our target categories would be expected to share some acts with introverted.

These expectations were largely confirmed. There were no acts that showed strong placement (e.g., greater than $25 \%$ ) in both the quarrelsome and submissive categories. This finding serves to confirm the expectation that these two categories are orthogonal to each other in the domain of interpersonal behavior. In contrast, several acts showed strong placement in both quarrelsome and introverted, as well as in submissive and introverted. The following acts showed strong sorting into both quarrelsome and introverted (percentage of judges sorting into the quarrelsome and introverted categories, respectively, given in parentheses): He (she) refused to be introduced to his (her) friend's friends $(55,65)$; $\mathrm{He}$ (she) refused to have sexual relations with his (her) partner $(40,35)$; He (she) refused to share his (her) presents with his (her) friends $(80,25)$; He (she) avoided the salesperson's offer of assistance (40, 55 ), and $\mathrm{He}$ (she) refused to learn how to drive $(55,35)$.

The submissive-introverted conjunction showed an even larger number of crossdispositional sortings: At the meeting, he (she) let the others monopolize the conversation $(75,75)$; He (she) entered the conversation only when spoken to $(50,85)$; $\mathrm{He}$ (she) avoided direct eye contact when the shop clerk spoke to him (her) (50, 80 ); $\mathrm{He}$ (she) refused to argue for his (her) own beliefs $(85,50)$; $\mathrm{He}$ (she) waited for the other person to choose a topic to discuss $(90,60)$; and seven others.

\section{Assessing Act Performance}

Within the act frequency approach, the assessment of the dispositions of specific individuals is based on monitored act trends over a period of observation. Analysis of the internal structure of dispositional constructs follows from the theoretical assumption that dispositions function as natural cognitive categories of acts (Buss \& Craik, 1983a) and guides the identification of acts that will count as prototypical instances of the disposition being assessed. The aggregation of manifested acts of an individual over a period of observation to yield an act trend index for assessment purposes follows from the theoretical assumption that dispositional asscrtions are summarizing statements concerning human conduct (Buss \& Craik, 1983a).

With rare exceptions, human judges are the most relevant (and in many cases the only) source of data for assessing act performance. Human recorders of acts may be the actor (self-report or S-data) or a variety of observers (O-data) such as 
the spouse, friend, acquaintance, social worker, clinical psychologist, ward staff, or psychiatrist. Recordings of observed acts may vary in the time elapsed from initial act observation, ranging from relatively immediate recording to progressively more retrospective recordings (such as an hour, a day, a week, a month, or a year later). Practical and conceptual issues involved in recording act performance are complex and are currently being explored. These issues include the amount of inference about internal motives and intentions needed to describe the act adequately, the degree of situational specificity and the base-rate of occurrence (Buss, 1985b).

\section{ACTS, DISPOSITIONS, AND PERSONALITY DISORDERS: APPLICATIONS TO CLINICAL ASSESSMENT}

The act frequency approach to clinical assessment entails challenges not encountered by the act frequency analysis of normal personality dispositions. Two additional complexities are: (1) the analysis of personality disorder syndromes, which subsume several subordinate dispositional constructs and may carry content not captured by their constituent individual dispositions, and (2) the necessity for using expert clinical or psychiatric judgment in the various phases of act nomination, prototypicality judgment, and act assessment. This section outlines three basic strategies provided by the act frequency approach to psychiatric diagnosis, and identifies procedures for addressing these issues.

The first strategy starts with trait-descriptive terms in ordinary language and identifies the most clinically-relevant dispositional constructs among them. Many clinically relevant dispositions in fact occur in the natural language, suggesting that trait-descriptive terms have evolved linguistically to describe aspects of the psychopathology of everyday conduct. Without adopting any psychiatric classification system now in use, this "naive" act frequency application employs act nominations, prototypicality ratings, and act performance assessments of clinically relevant dispositions such as anxious, bizarre, insane, perverted, exploitable, licentious, macabre, and misogynic. This first strategy possesses the advantage of potential discovery of important classes of acts in the psychopathology of everyday conduct. Its drawback is the overwhelming task faced by analysis of hundreds of dispositions.

The second act frequency strategy to clinical assessment starts with an existing classification system such as the DSM-III, much as our early work drew from the dispositions subsumed by the Wiggins (1979) circumplex model of interpersonal behavior. DSM-III descriptions of each disorder include a set of clinically-relevant dispositions that provide a starting point for act frequency analysis. For example, the paranoid personality disorder is described by the dispositions of suspicious, mistrustful, hypervigilant, guarded, secretive, jealous, cold, unemotional, humorless, unsentimental, hypersensitive, devious, scheming, argumentative, tense, critical, and litigious. This second strategy provides act nominations, prototypicality ratings, and act performance assessments of each of the subsumed dispositions.

The third strategy in clinical assessment takes the syndrome concept as the starting point, and attempts to unpack each syndrome in ways that might not be captured by the constituent individual dispositions it subsumes. This procedure includes direct act nominations for the syndrome, act nominations for pairs and triads of subsumed dispositions for each syndrome, prototypicality analysis of the acts and dispositions most relevant to the syndrome, and methods for identifying composite 
act portraits that best represent each syndrome. Each of these strategies entails some steps that call for expert psychodiagnostic judgments (e.g., identifying the most salient dispositional constructs for each DSM-III personality disorder syndrome) and other steps that enlist a broader range of participants (e.g., nominating acts of suspiciousness, vanity, and so on). For the latter stages of the procedures, it would be desirable to gather nominations from astute observers of social conduct such as journalists, playwrights, and the general public, as well as from clinical psychologists, psychiatrists, and social workers. The specific procedures for the three strategies are described in greater detail below.

\section{Strategy 1: Identifying Clinically Relevant Dispositions from the Natural Language}

The first act frequency strategy takes as its starting point clinically relevant dispositional constructs appearing in the natural language. This lexical approach starts with the basic assumption that dispositional constructs have evolved in the natural language to capture important performance phenomena. As described by Norman (1963), "perceptible differences between persons in their characteristic manner of behaving or changes over time and situations of single individuals in these regards have become codified as a subset of the descriptive predicates of the natural language in the course of its development (p. 574)." Features of behavior that have endangered self or other persons (Maher, B. A., \& Maher, W. B., 1985; Maher, W. B., \& Maher, B. A., 1975), or that have caused subjective distress to self or others, or that show adaptive inflexibility, the tendency to generate self-defeating cycles, or tenuous stability under stress (Millon, 1981) have become codified as descriptive predicates in the natural language. The natural language provides an important starting point for the act frequency analysis of the psychopathology of everyday conduct.

Two descriptive categories appearing frequently in everyday discourse are "depressed" and "anxious." In a pilot study using university students as act nominators, cxamples of acts nominated for the depressed category were: I talked about suicide, I moped around all day, I listened to depressing music, I trudged when I walked, I called a friend and cried over the phone, I drank alcohol alone, I ate very little, and I told others all the bad things that happened to me. Examples of acts nominated for the anxious category were: I bit my nails, I could not sleep at night, I could not sit quietly, I smoked many cigarettes, I walked around the room shuffling objects about, and I wondered aloud what my friends thought of me (Van Metre, 1983).

This natural language strategy offers the advantage of cxploring important classes of everyday clinically relevant acts that may elude existing psychiatric classification systems. Included in Allport and Odbert's (1936) list of trait descriptive terms are, for example: caustic, chameleonic, exploitable, hypersensitive, idolatrous, inarticulate, inflammable, insatiable, intolerant, intractable, lachrymose, licentious, macabre, masochistic, maudlin, misogynic, and mysterious. These terms refer to classes of acts that do not appear to be readily subsumed by the DSM-III personality disorders, but may constitute important aspects of the psychopathology of everyday conduct.

Goldberg (1982) has reduced the Allport-Odbert listing of trait-descriptive terms from 17,954 to 1,710 more commonly used adjectival terms (e.g., abrupt, absentminded, abusive). Our own theoretical formulation provides criteria for deeming certain dispositions as more worthy of research attention than others (Buss \& Craik, 
1985). For the present purposes, however, the pertinent sub-set of this domain could be identified by having a panel of expert judges rate the terms on their clinical relevance to personality disorders in general.

\section{Strategy 2: Identifying Clinically Relevant Dispositions Subsumed By Each DSM-III Personality Disorder}

This strategy of clinical assessment starts with the assumption that the existing DSMIII classification system has already identified the most important psychiatric syndromes. Since each personality disorder on Axis II of the DSM-III contains rich trait-descriptive portraits, act frequency analysis can be applied to these syndromerelevant dispositions. For example, the histrionic personality disorder is described by the dispositions: exaggerated, self-focused, overreactive, irrational, angry, shallow, egocentric, inconsiderate, self-indulgent, vain, demanding, dependent, and helpless. Each of these dispositions can be unpacked by the act frequency methods of act nominations and prototypicality judgments. Act performance assessments can be monitored by self, family members, and relevant members of the psychiatric community.

An important issue in this application of the act frequency approach to psychiatric classification is that the DSM-III formulations also contain features that are not described in purely dispositional terms. A central characteristic specified for the narcissistic personality disorder, for example, is "entitlement," which denotes an expectation of special favors without assuming reciprocal responsibilities (American Psychiatric Association, 1980, p. 317). Among other things, entitlement might involve surprise and anger that others will not do what is wanted. Even though the term "entitlement" is not a trait-descriptive adjective, a sense of entitlement can nonetheless be treated as a category of acts and thus as dispositional. However, other diagnostic indicators may be more difficult to accommodate directly into dispositional terms (e.g., relationships that characteristically alternate between extremes of overidealization and devaluation) (American Psychiatric Association, 1980, p. 317).

This second strategy raises important questions about the links between acts, dispositions, and syndromes. Do the dispositional descriptions fully capture each syndrome? Can non-dispositional features such as entitlement be meaningfully treated as act categories and subjected to prototypicality analysis and performance assessment? Are there configural combinations of dispositions that more adequately represent each syndrome in ways that are missed by the single-dispositional unpacking of personality disorders? The third act frequency strategy provides empirical procedures for addressing these challenges.

\section{Strategy 3: Establishing Links Among Syndromes, Dispositions, and Acts}

The third strategy provides a set of methods for identifying the links among each personality disorder syndrome, the dispositions and non-dispositional terms it subsumes, and the acts that are prototypical for each of these units. ${ }^{1}$ The basic pur-

\footnotetext{
'Subsequent to the preparation of this article, initial research along the lines indicated has been undertaken by Livesley (1984). In his project, Livesley has secured prototypicality judgments from members of the Canadian Psychiatric Association and the American Psychiatric Association (total N:862). Each participant rated a list of either trait or behavior
} 
pose of this strategy is to identify which dispositions and acts best identify each personality disorder syndrome. This process includes methods (1) for designating which single dispositions are most central to each syndrome, (2) for bypassing dispositional analysis by proceeding directly to acts nominated for the syndrome itself, (3) for identifying conjoint categories of acts through configuring dispositions into pairs and triads, (4) for creating act portraits that best identify each syndrome, and (5) for act-based conceptual differentiation among personality syndromes. This section describes these procedures.

Dispositions Most Relevant to Each Syndrome. The first procedure consists of identifying which dispositions best represent each personality syndrome. Thus, among those falling under its description, prototypicality judgments are made evaluating how central each disposition is to each syndrome. Are "suspicious" and "hypervigilant," for example, more central to the paranoid syndrome than the dispositions "humorless" and "litigious"? This procedure also includes multi-dispositional prototypicality ratings vis-a-vis each syndrome. Is the combination of "self-focused, .demanding, and dependent" more prototypical of the narcissistic personality disorder than the combination "irrational, over-reactive, and angry"?

Conjoint Dispositional Act Nominations. The notion of syndromes can imply configurations of dispositions that differ from the sum of the constituent individual dispositions. The histrionic personality disorder, for example, may be better represented by acts that are simultaneously egocentric, self-dramatizing, and dependent. High frequencies of acts in each of these categories separately may not depict the histrionic personality syndrome as well as acts nominated conjointly for the dispositional categories. Therefore, the first step in recognizing syndromes within the act frequency approach involves act nominations within conjoint categories of dispositions.

For this purpose, individual dispositions subsumed by each syndrome can be configured into pairs and triads that represent all possible combinations. Acts nominated in this fashion would form the second pool of acts, in addition to the pool of acts generated by single-dispositional act nominations. Both sets will be used for subsequent portrait-matching and syndrome identification (see below).

DSM-III Syndrome Act Nominations. Even conjoint dispositional act nominations, however, may not fully or accurately capture the nature of acts denoted and connoted by the personality disorder syndromes. Thus, the third procedure for analysis at the syndrome level involves direct act nominations for each of the DSM-III personality disorder syndromes. Unlike single and conjoint dispositional act nominations, however, syndrome act nominations must employ professionals such

descriptors regarding prototypicality for one of the 11 personality disorders syndromes. The trait and behavior lists were derived from four major texts, including the DSM-III manual (American Psychiatric Association, 1980). Although our specification of trait and act units differs from those employed in this project, and our research agenda extends more broadly, the overall conceptual structures of the two approaches map onto each other very closely. The reports on this project will provide important empirical findings, and Livesley's presentation has already been recognized as the outstanding scientific paper at the 1984 meetings of the Canadian Psychiatric Association at Banff. 
as clinicians and psychiatrists. These act-syndrome nominations would form the third pool of acts, joining single and multi-dispositional act nominations, for developing composite act portraits of each personality syndrome.

Act Portraits and Syndrome Matching. The central purpose of these procedures is to produce act portraits that are accurately representative of each syndrome. These procedures for generating acts from single dispositions, from multi-dispositional conjunctions, and directly from each syndrome provide three pools of acts from which the act portraits of syndromes can be constructed and compared for goodnessof-fit with the syndrome.

Several alternative ways of combining acts into act portraits of a given personality disorder syndrome are available for comparative study. For the paranoid personality disorder, for example, a single act can be drawn from each of the most salient dispositional constructs for that syndrome. Thus, an act portrait might be generated by drawing a single specific prototypical act from each of the following dispositional constructs: argumentative, cold, devious, guarded, humorless, hypervigilant, jealous, litigious, mistrusting, secretive, scheming, serious, suspicious, tense, and unemotional. In a second method, the elements of the act portraits could be drawn from the pool of acts generated by the joint nomination of acts for dyads and triads of dispositional constructs. A third approach would employ acts nominated directly for the given personality disorder syndrome, rather than from acts nominated for their most salient dispositional constructs.

Multiple-Act Sortings, Syndrome Overlap, and Diagnostic Differentiation. The sharpness or fuzziness of psychiatric categories continues to be a major research issue (e.g., Cantor \& Genero, in press; Millon, 1981). The DSM-III personality disorders are not regarded as entirely discrete or orthogonal. Indeed, some dispositional descriptions are shared by two or more syndromes. The consistent drawing of attention to oneself (vain, exhibitionistic), for example, appears in the description of both narcissistic and histrionic personality disorders. Therefore, syndrome overlap and diagnostic differentiation are two crucial issues in clinical assessment.

The act frequency approach to the dispositional analysis of everyday conduct provides the method of multiple-act sorting to clarify these issues. This procedure involves presenting clinicians with the 11 personality syndromes, and requesting them to sort each act into the category or categories into which it belongs. Subsequent to each sort, judges rate each act on its degree of prototypicality for each of the syndromes into which it was sorted.

This sorting procedure yields several kinds of information. First, it identifies which acts belong equally to several syndromes, and are therefore not differentially diagnostic. Second, it identifies the acts that belong to one and only one syndrome, and therefore can be used as pathognomonic of the syndrome. Finally, it yields empirical information about the degree of act overlap hetween each of the 11 personality syndromes. This information provides a basis for examining the relations among the 11 personality disorder syndromes. It would also serve to gauge the extent to which that structure is similar to, or perhaps overlaps with, the structure of interpersonal dispositions (Widiger \& Frances, in press).

Figure 1 shows a graphic illustration of the three levels of analysis: syndromes, dispositions, and acts. Act nominations from a panel $(N=52)$ of undergraduates illustrate specific acts subsumed by dispositions relevant to the paranoid personality 


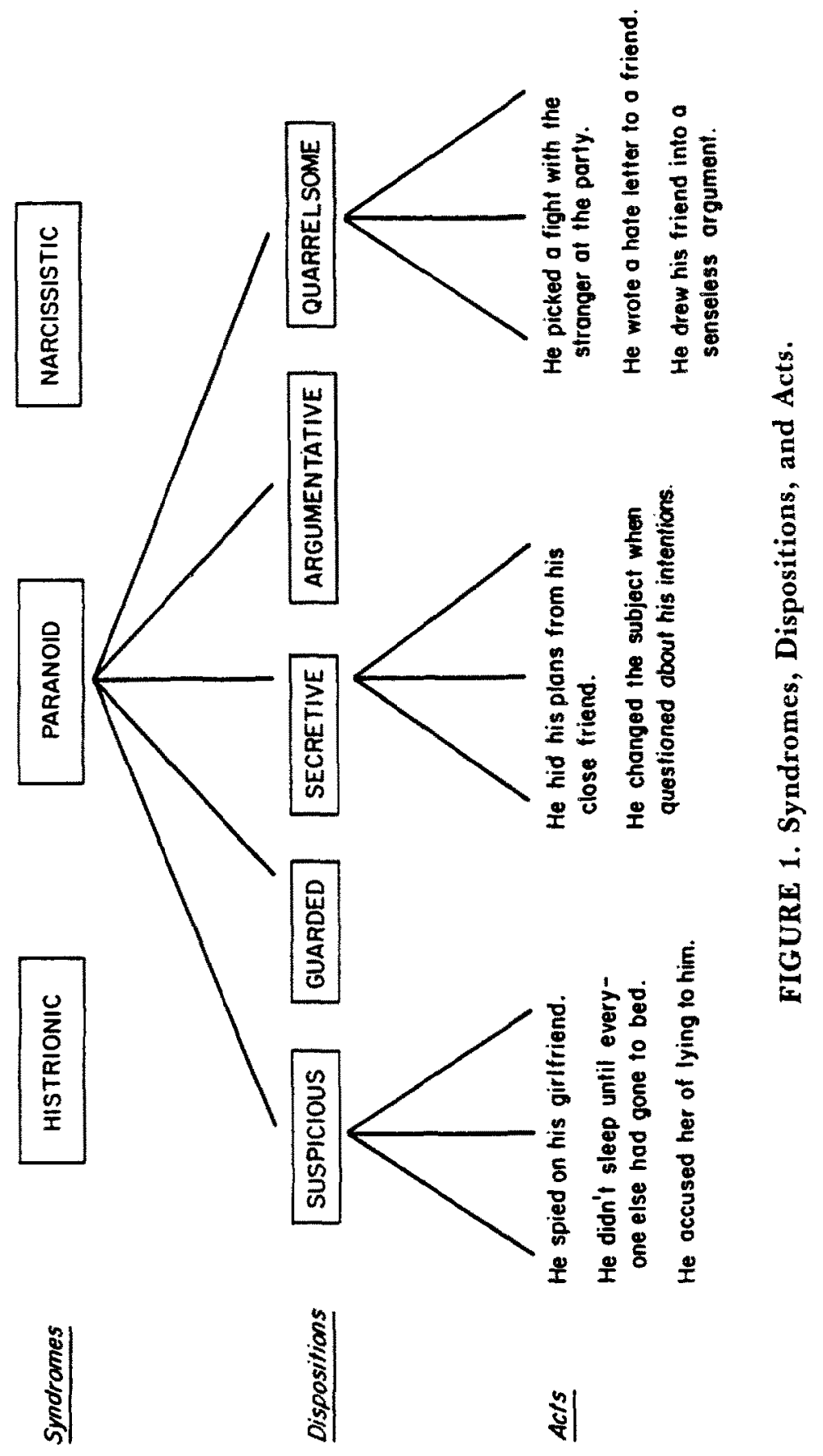


syndrome. The procedures outlined above provide a means for moving from syndromes to dispositions, from dispositions to acts, and from syndromes directly to acts. The prototypicality judgments and portrait matching procedures provide ways to identify the acts most relevant to each clinically-relevant disposition, as well as acts most relevant to the syndrome, directly or indirectly. The conjoint categorical procedures also provide methods for capturing the configural aspects of each personality syndrome.

\section{RELATION OF ACT FREQUENCY APPROACH TO OTHER STRATEGIES}

The act frequency approach to the psychopathology of everyday conduct carries implications for complementary assessment approaches. This section compares and contrasts our approach with personality scale assessment (e.g., MMPI), behavioral personality assessment (e.g., Goldfried \& Kent, 1972), and the recent prototype and exemplar strategies advanced by Cantor and her colleagues (Cantor et al., 1980; Cantor \& Genero, in press; Genero \& Cantor, 1985).

\section{Relation to Personality Scale Assessment}

Among the most widely used psychological assessment devices for psychiatric diagnosis are self-reported inventories such as the MMPI (Hathaway \& McKinley, 1943; Dahlstrom, Welsh, \& Dahlstrom, 1972, 1975). Clinical scales were constructed, typically through the method of criterion-keying, and diagnoses made from relative elevation of single scales or, more typically, through configural interpretation of scale combinations. The understanding of scales and profiles evolved progressively through a process formalized as construct validation (Cronbach \& Meehl, 1955). As more and more non-test correlates of each scale accrued, the construct considered to be assessed by each scale and scale combination evolved to accommodate the observed empirical correlates. In this strategy, the scales and profiles tend to be primary, and each associated conceptual formulation expands as an inductive summary of external correlates (Buss \& Craik, 1983b).

In contrast, in the act frequency approach to clinical assessment, the "external correlates" themselves are taken as the primary focus of assessment. That is, the frequencies of everyday acts prototypic of clinically relevant dispositions form the most central diagnostic focus. Even in the case of personality scales, monitored act trends serve as an important source of validational information (Buss \& Craik, 1983b).

\section{Relation to Cantor's Prototype and Exemplar Assessment Strategies}

In a series of papers, Cantor and her collcagues have formulated an approach to psychiatric diagnosis that attends closely to recent innovations in the psychology of natural categorization. A basic premise of this approach is that psychiatric categories, like natural cognitive categories of objects, are "fuzzy" in two senses. First, there is fuzziness within categories that produces some ambiguity in "what a target instance is." Category members thus differ from each other in "goodness of fit" to the category. Second, there is fuzziness between adjacent categories that introduces difficulties in knowing "what a target category isn't" (Cantor \& Genero, in press; Horowitz, Wright, Lowenstein, \& Parad, 1981). Category overlap can result, for example, from imperfect feature nesting; features central to superordinate categories (e.g., fruit) may not be invariably characteristic of subordinate categories 
(e.g., tomato). Category fuzziness in both senses renders clear and unambiguous criterial assignment of instances to categories difficult.

Two approaches to natural categorization that analyze within-category fuzziness are the prototype model of representation (e.g., Rosch \& Mervis, 1975) and the exemplar model of representation (Smith \& Medin, 1981). The prototype model is based on similarity matching where instances are evaluated against a prototype, or theoretical ideal. Close approximation to the prototype yields categorization of instances as central to the concept. Progressively weaker approximation to the prototype produces more peripheral categorization of included members. In the domain of natural categories, robins and sparrows are judged more similar to the ideal prototype "bird" than are penguins and turkeys, which would be considered peripheral members of the category "bird" because of their poorer approximation of the ideal or prototypical bird.

The exemplar model of categorization differs from the prototype model in that it recognizes explicitly that there can be many ways to approximate a category ideal. Therefore, an exemplar-based categorization procedure entails multiple concrete examples for comparative purposes in determining category membership. Categorizers, in the exemplar model, would retrieve many good examples of birds (e.g., robins, sparrows, bluejays, canaries), and compare the target instance with these multiple examples rather than with a single idealized prototype. In this latter model, category inclusion occurs if the instance matches at least one of the retrieved examples.

Cantor has used both protoytpe and exemplar representations for application to clinical diagnosis. For example, Cantor and Genero (in press) concluded that summary prototypes may be most useful for novices in grasping the fuzzy structure of diagnostic categories. In contrast, experts appear to distinguish typical from atypical cases with greater confidence using an exemplar model. Procedures are also provided for distinguishing different categories from each other.

The act frequency approach to clinical assessment accords well at several junctures with Cantor's natural categorization approach. First, the approaches are in agreement about the intrinsic fuzziness of natural and psychiatric categories. Clinical membership is continuous rather than discrete, and categories show feature overlap. Second, within both approaches, there are alternative paths to reaching the same diagnosis. Within Cantor's approach, alternative combinations of features can produce similar diagnoses. Within the act frequency approach, different combinations of act trends of diagnostically-relevant dispositions, as well as different act portraits, can yield similar diagnostic classification.

Finally, the procedures developed by Cantor and Genero (in press) for similaritymatching can be employed within the act frequency approach. Act portraits derived in various ways by the procedures described earlier can be employed in the CantorGenero similarity matching paradigm. These procedures in combination can be expected to clarify the thorny issucs of syndrome overlap and diagnostic differentiation.

\section{Relation to Behavioral Assessment}

Although behavioral assessment carries different meanings for different investigators and practitioners, several core features can be extracted and compared with the act frequency approach (Goldfreid \& Kent, 1972; Hartmann, Roper, \& Bradford, 1979; Mash, 1979). Both approaches focus on what the person does, both emphasize 
the study of behavior in natural contexts, and both treat specific behaviors as samples from designated domains. Beyond these similarities, the act frequency approach diverges from that of behavioral assessment on four key points.

First, the two approaches differ in the nature of the categories of behavior that guide their research strategies. The act frequency approach begins with dispositional constructs drawn from everyday language, and treats them as cognitive categories of acts whose internal (e.g., prototypicality) structure and manifested (i.e., occurrence frequency) structure can be studied. In contrast, behavioral assessment focuses on categories of behavior relevant to situations that are problematic for clients in therapy. In addition, behavioral assessment categories often function as skill or ability constructs in the sense that the behaviors are typically evaluated against a standard of effectiveness in dealing with problematic situations. Because of these differences between the two approaches, behavioral assessment typically involves a detailed analysis of situation-specific behavioral descriptions. In contrast, the act frequency approach operates at the dispositional level by aggregating single acts into act trends or multiple-act indices (Buss \& Craik, 1983a).

A second major contrast between the two approaches centers around the issues of prediction and control. Behavioral assessment is often focused on monitoring behavioral change, and therefore tends to minimize temporal stability and prediction. The act frequency approach is explicitly concerned with documenting various forms of temporal stability (Buss, 1985b), particularly at the level of act trends or multiple-act indices. Thus, there is a greater emphasis on prediction and description within the act frequency approach, while behavioral assessment emphasizes therapy interventions and the monitoring of behavioral change.

A third important differentiating feature centers around the presumed causes of behavior. Behavioral assessment typically locates the causes of behavior in maintaining conditions within the current environment. In contrast, the key constructs within the act frequency approach - dispositions - are viewed as performing descriptive rather than explanatory functions regarding specific behaviors. Thus, the identification of causal factors for individual differences in act trends is viewed as an open issue, and can encompass both organismic and environmental agents.

Finally, behavioral assessment is primarily idiographic in application. Unique behaviors of specific individuals are targeted for assessment and intervention. In contrast, the act frcquency approach tends to be morc nomothctic, although it can be deployed for idiographic analysis as well (Buss \& Craik, 1983c, 1984).

\section{IMPLICATIONS AND CONCLUSIONS}

The act frequency approach to the psychopathology of everyday conduct carries several important implications. They include the conceptual analysis of personality disorders, implications for clinical assessment techniques for each disorder, and the course by which conduct in everyday life eventually may lead to psychiatric diagnosis in more formal settings. This section briefly considers these issues.

The act frequency approach to the DSM-III personality disorders highlights the important role of everyday conduct in understanding each syndrome. While the DSM-III provides dispositional descriptions of each disorder, identifying of the act manifestations subsumed by these dispositions (singly and in conjunction), and by the syndromes themselves, remains a central research task. Unpacking the act manifestations of each syndrome can be expected to clarify conceptual issues such 
as diagnostic differentiation, as well as illustrating the rich diversity of acts that may be subsumed by each syndrome considered alone. This report is a first effort at exploring the usefulness of the act frequency approach for our understanding of psychiatric diagnosis and personality disorders.

Two strategies have been described for identifying clinically relevant dispositions that are encoded in everyday language. In the first strategy, the entire array of major trait terms is scanned for psychiatric pertinence through the use of expert clinical judgment. In the second strategy, the most salient dispositional terms for each of the 11 personality disorder syndromes of the DSM-III are identified. Together, these two strategies establish a meaningful sub-set of dispositional terms relevant to clinical assessment and available for act prototypicality analysis.

The third strategy adopts the syndrome itself as an additional level of analysis and explores the relations among syndromes, the dispositions they subsume, and the act manifestations of syndromes, both directly and through their salient dispositions (see Figure 1). We suggest empirical procedures for linking these three levels of analysis, and for testing alternative act portraits for their goodness-of-fit to each syndrome.

Because clinical assessment often occurs in settings removed from ordinary life, our strategy provides methods for translating diagnostic classifications back to their original referents in everyday conduct. Thus, the act frequency approach views dispositions as categories of acts whose internal and manifested structures can be explored. We anticipate that these methods of unpacking the everyday referents for diagnostic categories and their subsumed dispositions will yield hundreds or thousands of acts that directly illuminate the psychopathology of everyday conduct.

One possible outcome of these analyses is that many of the acts generated directly from syndrome-derived dispositions will not themselves be judged to be clinically relevant. The dispositional term "dependent," for example, may be judged relevant to the histrionic personality disorder. But only a subset of prototypically dependent acts may be directly relevant to the histrionic syndrome, or in any other way clinically pertinent. Perhaps combinations of dependent acts with acts prototypical of other histrionic-relevant dispositions (e.g., self-dramatizing) may be judged more pertinent to histrionic personality disorder than prototypically dependent acts in isolation. In addition, base-rate considerations may be relevant to diagnosis, with high frequencies of dependent acts needed before classification in the histrionic category is warranted. The act frequency approach provides a means for examining how patterns of everyday conduct combine as portraits of a particular personality disorder.

Specific personality disorder syndromes can be conceptually clarified by their translation into act portraits drawn from the context of everyday action. These act portraits can be used to illuminate the nature of each syndrome, and to gauge the overlap and distinctiveness of each of the 11 DSM-III personality disorders. Multiple act sorting procedures offer a means for determining which syndromes share few or many prototypical dispositions and acts. The structural relations among the syndromes can be determined by these procedures. The structural relations also can be examined for potential mapping onto the structure of interpersonal dispositions, as Widiger and his colleagues advocate (Widiger \& Frances, in press; Widiger \& Kelso, 1983).

The relations between dispositional terms in ordinary language and the formal psychiatric classifications of personality disorders warrant some final observations. 
The theoretical orientation of the act frequency approach leads us to our present focus - viewing dispositional constructs as intermediary between syndromes and pertinent acts (see Figure 1). The success of translating syndromes into dispositions and then into acts, however, remains an empirical challenge. Our assumption is that the translation will be adequate and the opportunity for discovering new and unanticipated facets of the personality disorders will more than justify this effort.

Our analysis highlights several important differences between dispositional terms and the psychiatric categories of personality disorders. They differ in their origins, explicitness, and structure. We have speculated elsewhere (Buss \& Craik, 1983a) about the mysterious origins of dispositional constructs, viewing them as emergents of socio-cultural evolution. In contrast, the history of psychiatric diagnosis is well documented (American Psychiatric Association, 1980; Millon, 1981). Second, usage of dispositional terms in ordinary language is subject to indigenous cultural change and variation; in contrast, the psychiatric classifications are codified, changes are subject to expert balloting, and specific training in usage is conducted. Finally, within our framework, dispositional constructs are viewed as categories of one kind of element - the act. Personality disorder syndromes appear to be more heterogeneous categories, entailing acts, dispositions, inferred cognitive states, appearance, demeanor, institutional outcomes such as expulsion from school, and other components.

Interestingly, many of the key designating terms for the 11 personality disorders, such as paranoid, narcissistic, and histrionic, appear as trait-descriptive terms in ordinary language (see Allport \& Odbert, 1936). Thus, a case can be made for the primacy of dispositional constructs, and for the view that at least some of the psychiatric categories for the personality disorders represent expert embellishments of them.

Finally, we note that the present articulation of the act frequency approach in the context of psychiatric classification is not limited to the DSM-III personality syndromes. The same procedures can be extended to other typological systems such as Shapiro's (1965) neurotic styles, or the Jungian system of types (Jung, 1923). Most importantly, it provides a method for tying any psychiatric classification system directly to the psychopathology of everyday conduct.

\section{REFERENCES}

Abelson, R. P. (1981). Psychological status of the script concept. American Psychologist, 36, 715-729. Allport, G. W., \& Odbert, H. S. (1936). Trait-names: A psycholexical study. Psychological Monographs, 47, (Whole No. 211).

American Psychiatric Association (1980). Diagnostic and Statistical Manual of Mental Disorders (DSMIII). Washington, DC: Author.

Buss, D. M. (1985a). The act frequency approach to the interpersonal environment. Perspectives in personality 1, 173-200.

Buss, D. M. (1985b). The temporal stability of acts, trends, and patterns. In C. Spielberger \& J. N. Butcher (Eds.), Advances in personality assessment (Vol. 5, pp. 165-196). Hillsdale, NJ: Erlbaum.

Buss, D. M., \& Craik, K. H. (1980). The frequency concept of disposition: Dominance and prototypically dominant acts. Journal of Personality, 48, 379-392.

Buss, D. M., \& Craik, K. H. (1981). The act frequency analysis of interpersonal dispositions: Aloofness, gergariousness, dominance, and submissiveness. Journal of Personality, 49, 174-192.

Buss, D. M., \& Craik, K. H. (1983a). The act frequency approach to personality. Psychological Review, 90, 105-126.

Buss, D. M., \& Craik, K. H. (1983b). Act prediction and the conceptual analysis of personality scales: Indices of act density, bipolarity, and extensity. Journal of Personality and Social Psychology, 45, $1081-1095$. 
Buss, D. M., \& Craik, K. H. (1983c). The dispositional analysis of everyday conduct. Journal of Personality, 51, 393-412.

Buss, D. M., \& Craik, K. H. (1984). Acts, dispositions, and personality. In B. A. Maher \& W. B. Maher (Eds.), Progress in experimental personality research: Normal personality processes (Vol. 13, pp. 241-301). New York: Academic Press.

Buss, D. M., \& Craik, K. H. (1985). Why not measure that trait? Alternative criteria for identifying important dispositions. Journal of Personality and Social Psychology, 48, 934-946.

Buss, D. M., \& Craik, K. H. (in press). The act frequency approach and the construction of personality. In A. Angleitner, A. Furnham, \& G. Van Heck (Eds.), Personality psychology in Europe. Lisse, The Netherlands: Swets \& Zeitlinger.

Buss, D. M., \& Craik, K. H. (1986). The multiple dispositional categorization of acts. Manuscript in preparation.

Cantor, N., \& Genero, N. (in press). Psychiatric diagnosis and natural categorization: A close analogy. In T. Millon \& G. Klerman (Eds.), Contemporary issues in psychopathology. New York: Guilford Press.

Cantor, N., Smith, E. E, French, R., deSales, \& Mezzich, J. (1980). Psychiatric diagnosis as prototype categorization. Journal of Abnormal Psychology, 89, 181-193.

Cattell, R. B. (1946). Description and measurement of personality. Yonkers, NY: World Book Company.

Cronbach, L. J., \& Meehl, P. E. (1955). Construct validity in psychological tests. Psycholugical Bulletin, 52, 281-302.

Dahlstrom, W. G., Welsh, G. S., \& Dahlstrom, L. E. (1972, 1975). An MMPI handbook (Vol. I \& II). Minneapolis: University of Minnesota Press.

Genero, N., \& Cantor, N. (1986). Exemplar prototypes and clinical diagnosis: Towards a cognitive economy. Journal of Social and Clinical Psychology, (in press).

Goldberg, L. R. (1982). From ace to zombie: Some explorations in the language of personality. In C. D. Spielberger \& J. N. Butcher (Eds.), Advances in personality assessment (Vol. 1, pp. 203-234) Hillsdale, NJ: Erlbaum.

Goldfreid, M. R., \& Kent, R. N. (1972). Traditional versus behavioral personality assessment: A comparison of methodological and theoretical assumptions. Psychological Bulletin, 77, 409-420.

Hartmann, D. P., Roper, B. L., \& Bradford, D. C. (1979). Some relationships between behavioral and traditional assessment. Journal of Behavioral Assessment, 1, 3-21.

Hathaway, S. R., \& McKinley, J. C. (1943). The Minnesota Multiphasic Personality Inventory (Rev. Ed.). Minneapolis: University of Minnesota Press.

Horowitz, L. M., Wright, J. C., Lowenstein, E., \& Parad, H. W. (1981). The prototype as a construct in abnormal psychology: A method for deriving prototypes. Journal of Abnormal Psychology, 90, 568-574.

Jung, C. C. (1923). Psychological types. London: Routledge \& Kegan Paul.

Livesley, W. J. (1984). Criteria for the diagnosis of personality disorder: A comparison of hehavioral and dispositional prototypes. Paper presented to the Canadian Psychiatric Association Annual Meeting, Banff.

Maher, B. A., \& Maher, W. B. (1985). Psychopathology: II. From the eighteenth century to modern times. In G. A. Kimble \& K. Schlesinger (Eds.), Topics in the history of psychology (Vol. 2, pp. 295-329). Hillsdale, NJ: Erlbaum.

Maher, W. B., \& Maher, B. A. (1985). Psychopathology: I. From ancient times to the eighteenth century. In G. A. Kimble \& K. Schlesinger (Eds.), Topics in the history of psychology (Vol. 2, pp. 251-294). Hillsdale, NJ: Erlbaum.

Mash, E. J. (1979). What is behavioral assessment? Behavioral Assessment, 1, 23-29.

Millon, T. (1981). Disorders of personality. DSM-III: Axis II. New York: Wiley.

Norman, W. T. (1963). Toward an adequate taxonomy of personality attributes: Replicated factor structure in peer nomination personality ratings. Joumal of Abnormal and Social Psychology, 66, 574-583.

Rosch. E. (1975). Cognitive reference points. Cognitive Psychology, 7, 532-547.

Rosch, E., \& Mervis, C. B. (1975). Family resemblances: Studies in the internal structure of categories. Cognitive Psychology, 7, 573-605.

Rosch, E., Simpson, C., \& Miller, R. S. (1976). Structural bases of typicality effects. Journal of Experimental Psychology: Human Perception and Performance, 2, 491-502.

Shapiro, D. (1965). Neurotic styles. New York: Basic Books.

Smith, E. E., \& Medin, D. L. (1981). Categories and concepts. Cambridge, MA: Harvard University Press

Van Metre, H. J. (1983). Adjustment, anxiety, depression, and maladjustment: An empirical exploration from the at frequency approach, Unpublished honors thesis, Harvard University, Cambridge, MA.

Widiger, T. A., \& Frances, A. (in press). The DSM-III personality disorders: Perspectives from psychology. Archives of general psychiatry. 
Widiger, T. A., \& Kelso, K. (1983). Psychodiagnosis of Axis II. Clinical Psychology Review, 3, $491-510$.

Wiggins, J. S. (1979). A psychological taxonomy of trait descriptive tcrms: The interpcrsonal domain. Journal of Personality and Social Psychology, 37, 395-412.

Wiggins, J. S. (1980). Circumplex models of interpersonal behavior. In L. Wheeler (Ed.), Revieit of personality and social psychology (Vol. 1, pp. 265-294). Beverly Hills, CA: Sage.

Wiggins, J. S. (1981). Clinical and statistical prediction: Where do we go from here? Clinical Psychology' Review, 1, 3-18.

Wiggins, J. S. (1982). Circumplex models of interpersonal behavior in clinical psychology. In P. C. Kendall \& J. N. Butcher (Eds.), Handbook of research methods in clinical psychology (pp. 183-221). New York: John Wiley \& Sons.

Zadeh, L. A., Fu, K. S., Tanaka, K., \& Shimura, M. (Eds.), (1975). Fuzzy sets and their application to cognitive and decision processes. New York: Academic Press. 